\title{
High-temperature mechanical behavior of polycrystalline yttrium-doped barium cerate perovskite
}

C. Vaquero-Aguilar (a), M.J. López-Robledo (a), J. Martínez-Fernández (a), C. Real (b), M. Jiménez-Melendo (a)

(a) Departamento de Física de la Materia Condensada, Universidad de Sevilla, Aptdo. 1065, 41080 Sevilla, Spain

(b) Instituto de Ciencias de Materiales de Sevilla, Universidad de Sevilla-CSIC, Av. Americo Vespucio 49, 41092 Sevilla, Spain

\begin{abstract}
The high-temperature mechanical properties of the mixed ionic-electronic conductor perovskite $\mathrm{BaCe} 0.95 \mathrm{Y} 0.05 \mathrm{O} 3-\delta$ with average grain size of $0.40 \mu \mathrm{m}$ have been studied in compression between 1100 and $1300{ }^{\circ} \mathrm{C}$ in air at different initial strain rates. The true stress-true strain curves display an initial stress drop, followed by an extended steadystate stage. As the temperature decreases and/or the strain rate increases, there is a transition to a damage-tolerant strain-softening stage and eventually to catastrophic failure. Analysis of mechanical and microstructural data revealed that grain boundary sliding is the primary deformation mechanism. The strength drop has been correlated with the growth of ultrafine grains during deformation, already present at grain boundaries and triple grain junctions in the as-fabricated material.
\end{abstract}

\section{Keywords}

D. Perovskites; C. Creep; A. Sintering; B. Microstructure-final; A. Grain growth

\section{Introduction}

Perovskite-structured oxides of generic formula $\mathrm{ABO} 3$ (where $\mathrm{A}$ and $\mathrm{B}$ denote site cations) have received increasing attention in the last years because the selective $\mathrm{A}$ and B site doping provides a unique opportunity for tailoring their properties for important practical applications, particularly in the field of electrochemical energetics as electrolytes in solid oxide fuel cells (SOFCs) and chemical sensors.1, 2, 3, 4, 5, 6 and 7 Substitution of B4+ sites by trivalent ions in these perovskite oxides causes the formation of oxygen vacancies, which allow for protonic conduction (hydrogen ion transport) rather than the more familiar oxygen ion conduction. Because of the higher mobility of protons, the operating temperature of SOFCs can be safely reduced without degrading performance. 8 and 9

Yttrium-doped barium cerate (BCY) is a prototype of this class of proton conducting oxides. It exhibits one of the highest proton conductivities at elevated temperatures, as 
well as an excellent chemical stability over a large range of temperatures and oxygen partial pressures.10, 11 and 12 In addition, it has been recently discovered that BCY also exhibits remarkable steam-permeation capabilities under appropriate conditions, 13 and 14 that can be used to improve the performance of a variety of energy conversion technologies including SOFCs, membrane reformers and coal gasification. Most of the investigations on BCY are concerned with its processing, structure, defect chemistry and conductivity characteristics. Only two studies, however, have focused on the hightemperature mechanical properties of these high-temperature proton conductors. 15 and 16 These properties are of special relevance in the design of components and system architectures in SOFCs and other high-temperature operating devices, which are typically submitted to creep conditions: deformation, mechanical degradation and failure determine the material behavior and ultimate overall performance. Creep studies of perovskites are also important for understanding the deformation behavior of the Earth's lower mantle.17 and 18 In addition, high-temperature plastic deformation is usually controlled by diffusion, and can thus provide basic information about mass transport in the compound. Since sintering and grain growth are governed by diffusional processes, such an information can be used to devise optimum processing schedules.

Therefore, the objective of this work was to investigate the high-temperature mechanical behavior of fine-grained $\mathrm{BaCe} 0.95 \mathrm{Y} 0.05 \mathrm{O} 3-\delta$ polycrystals fabricated by solid state reaction. Deformation curves were obtained in air at various constant displacement rates in the temperature range between 1100 and $1300{ }^{\circ} \mathrm{C}$. The mechanical data were correlated with microstructural observations to deduce the deformation mechanisms.

\section{Experimental procedure}

\subsection{Sample preparation}

$\mathrm{BaCe} 0.95 \mathrm{Y} 0.05 \mathrm{O} 3-\delta$ (BC5Y) powders were prepared by solid-state reaction of $\mathrm{BaCO} 3$, $\mathrm{CeO} 2$ and $\mathrm{Y} 2 \mathrm{O} 3$ powders (Aldrich, purity $>99.0 \%$ ). The raw materials were weighted in the required stoichiometric ratio, mixed and grounded in agate media for $1 \mathrm{~h}$ using a planetary ball mill. The resulting powder was calcined for $10 \mathrm{~h}$ at $1200{ }^{\circ} \mathrm{C}$ in air and then manually crushed to reduce agglomerates. X-ray diffraction analysis confirmed that the resulting powder was pure orthorhombic perovskite phase. The powder was uniaxially pressed at $150 \mathrm{MPa}$ into $20 \mathrm{~mm}$-diameter pellets and then isostatically cold pressed at $210 \mathrm{MPa}$. A two-step sintering process was performed on the pellets in air atmosphere at low heating and cooling rates: a first step at $600{ }^{\circ} \mathrm{C}$ for $2 \mathrm{~h}$ to eliminate water and hydroxides formed during intermediate stages, and a second sintering step at $1550{ }^{\circ} \mathrm{C}$ for $10 \mathrm{~h}$. The final density of the samples, determined using Archimedes' method, was about $90 \%$ of the theoretical value $(6310 \mathrm{~kg} / \mathrm{m} 3)$.

\subsection{Mechanical tests and microstructural observations}

Specimens of $5 \times 3 \times 3 \mathrm{~mm}$ in size were cut from the sintered pellets with a low-speed diamond saw and used for mechanical testing. Compression tests were carried out at 
temperatures $\mathrm{T}$ between 1100 and $1300{ }^{\circ} \mathrm{C}(0.74 \mathrm{Tm}<\mathrm{T}<0.85 \mathrm{Tm}$, where $\mathrm{Tm}=1850 \mathrm{~K}$ is the melting temperature of $\mathrm{BaCeO} 3$ ) in air at constant cross-head speed. The specimens were sandwiched between CSi pads in order to reduce the friction with the alumina push rods of the deformation machine, which tends to cause plastic constrictions at either end of the specimen. The recorded data, load vs time, were plotted as $\sigma-\varepsilon$ curves, where $\sigma$ is the true stress and $\varepsilon$ is the true strain. Mechanical tests were discontinued after reaching a total true strain of $50 \%$ for subsequent microstructural observations.

The data were analyzed using the standard high-temperature power law for steady-state deformation:

$\dot{\varepsilon}=A \sigma^{n} d^{-P} \exp \left(-\frac{Q}{R T}\right)$

where $\mathrm{A}$ is a parameter depending on the deformation mechanism, $\mathrm{d}$ is the grain size, $\mathrm{n}$ is the stress exponent, $\mathrm{p}$ is the grain size exponent, $\mathrm{Q}$ is the activation energy for flow and $\mathrm{R}$ is the gas constant.

\subsection{Microstructural observations}

The microstructural characterization of as-fabricated and deformed polycrystals was carried out using conventional (SEM) and high-resolution (HRSEM) scanning electron microscopy (Microscopy Service, University of Sevilla, Spain). To reveal grain boundaries, longitudinal sections were cut from the samples and mechanically polished using up to $1 \mu \mathrm{m}$ grade diamond paste, and then thermally etched at $1200{ }^{\circ} \mathrm{C}$ for $2 \mathrm{~h}$ in air. The relevant morphological parameters, grain size $\mathrm{d}$ (taken as the equivalent planar diameter $\mathrm{d}=(4($ grain area $) / \pi) 1 / 2)$ and form factor $\mathrm{F}$ (defined as $\mathrm{F}=4 \pi($ grain area)/(grain perimeter)2) were measured by using a semiautomatic image analyzer. Fracture surfaces were also analyzed by HRSEM; in as-fabricated and non-fractured strained specimens, fracture surfaces were obtained through breaking the samples by impact at room temperature.

\section{Experimental results}

Fig. 1 shows a HRSEM micrograph of a polished and thermally etched cross-section of the fabricated material. The grains appear to have an equiaxed shape $(F=0.80)$, with an average grain size $\mathrm{d}$ of $0.40 \mu \mathrm{m}$. Porosity consisted in cavities at multiple grain junctions, with pore sizes of a few micrometers.

Typical true stress $\sigma$-true strain $\varepsilon$ curves are shown in Fig. 2 for different deformation conditions of strain rate and temperature. As noted above, tests were usually ended at $50 \%$ strain for a better observation of the resulting microstructure, unless premature fracture occurred. The compound exhibits a transition from ductile to fragile behavior as the initial strain rate increases or the temperature decreases. Several characteristics may be noticed from this figure: 
In the ductile region (that is, at lower strain rates and higher temperatures), the curves exhibit a peak stress at the beginning of the deformation, followed by a controlled stress drop and then by an extensive secondary creep regime (characterized by a positive slope of the $\sigma-\varepsilon$ curve due to the increase in specimen section and true strain rate during compression). There is a progressive transition from ductile to fragile behavior when increasing the initial strain rate and/or decreasing the temperature. The onset of material degradation is characterized by a slow decrease in flow stress with increasing strain, as can be seen in the $\sigma-\varepsilon$ curve for View the MathML source in Fig. 2a. Despite the damage, the material still retains a relatively high strength after the completion of the test in this semibrittle regime (curve for $\mathrm{T}=1200{ }^{\circ} \mathrm{C}$ in Fig. 2b), indicating the attainment of a damage-tolerant regime in such experimental conditions Eventually, at the worst testing conditions of strain rate and temperature, catastrophic failure occurred after relatively small strains.

The magnitude of the stress drop (the difference between upper and lower yield stresses) decreases when decreasing the strain rate and/or increasing the temperature. The ratio between the peak stress and the minimum stress is, however, practically constant with a value of 1.10. This result suggests that the mechanism responsible for the initial strength drop is the same at all deformation conditions.

The critical strain $\varepsilon p$ at which the peak stress $\sigma p$ and subsequent softening takes place also shifts slightly to lower strains with increasing temperature and/or decreasing strain rate.

The mechanical characteristics of BC5Y polycrystals in the ductile region (strength drop followed by steady-state deformation, and variation of $\sigma p$ and $\varepsilon p$ with the two control variables View the MathML source and T) are very similar to those reported for various metals and alloys at hot deformation conditions. 19, 20, 21, 22 and 23 On the contrary, very few studies have reported the occurrence of yield drop in ceramic polycrystals, 24 and 25 particularly at small grain sizes.26 To our knowledge, no such a behavior has been found on similarly structured perovskites.

The macroscopic aspect of the strained samples is well correlated with the mechanical behavior displayed by the corresponding stress-strain curves. Except for the most severe deformation conditions where catastrophic failure occurred, the samples underwent a rather homogeneous deformation without barreling. No special features were observed for samples exhibiting steady-state flow. As the temperature decreased and/or the initial strain rate increased, macroscopic cracks parallel to the loading direction were visible on the lateral surfaces, corresponding to samples with controlled degradation. As noted previously, the material was tolerant to these macrocracks even after strains of $50 \%$ in compression. Finally, these cracks developed faster at highest strain rates and lowest temperatures, fracturing the sample into small pieces.

Fig. 3 shows a polished and thermally etched longitudinal cross-section of a sample deformed in steady-state conditions $\left(\mathrm{T}=1300{ }^{\circ} \mathrm{C}\right.$, View the MathML source, $\left.\varepsilon=50 \%\right)$. The grains remain equiaxed, indicating that grain boundary sliding is the primary 
deformation mechanism at such experimental conditions, as usually found in finegrained superplastic metals and ceramics. 27 and 28 As $\mathrm{T}$ decreases or View the MathML source increases, grain boundary sliding is not fast enough to accommodate the deformation imposed, and cracks develop along grain boundaries leading eventually to failure. A close inspection of Fig. 3 reveals that the average grain size is slightly smaller than that for the as-fabricated material due to the presence of new fine grains of about $100 \mathrm{~nm}$ in size. This finding can be better observed in Fig. 4, which shows HRSEM micrographs of vertical fracture surfaces obtained under various experimental conditions. In the as-fabricated material (Fig. 4a), the grain boundaries and triple junctions are decorated with ultrafine grains smaller than $20 \mathrm{~nm}$ in size; these grains increase up to about $100 \mathrm{~nm}$ in size during steady-state deformation (Fig. 4b). A similar evolution of the grain structure was observed in samples that failed during testing (Fig. 4c).

\section{Discussion}

The mechanical characteristics displayed by the $\sigma-\varepsilon$ curves of BC5Y indicate the occurrence of a softening mechanism prior to the establishment of the steady-state flow, leading to a peak in stress. Morita et al.26 have recently reported yield drop in a finegrained $(\mathrm{d}<1 \mu \mathrm{m})$ tetragonal $\mathrm{ZrO} 2-30$ vol\% spinel composite, which was attributed to a sudden increase in the mobile dislocation density in spinel grains. Similarly, Dokko and Pask24 ascribed the yield drop in large-grained $\mathrm{MgO}(\mathrm{d}>10 \mu \mathrm{m})$ to dislocation multiplication in different slip systems. These intragranular dislocation-related mechanisms, also found in single crystals, usually result in rather sharp stress drops, which are little affected by strain rate. In the present work, all yield curves are of rounded configuration, and the yield stresses strongly depend on the strain rate (and temperature). This behavior is very similar to what has been reported in the hot deformation of metals and alloys, 19, 20, 21, 22 and 23 in which the peak stress and steady-state flow result from a dynamic balance between dislocation recovery and dynamic recrystallization. The microstructural evolution observed during mechanical testing of BC5Y (Fig. 4), along with the variation in peak stress and strain values with temperature and strain rate conditions, suggests that the growth of the ultrafine grains under deformation is responsible for the peak stress and subsequent controlled strength drop. At the beginning of the deformation, the ultrafine grains are so small that "normal" neighbor grains are in contact with each other; these normal grains, with an average grain size d, thus will carry the imposed load at a stress level given by Eq. (1). As the deformation progresses, the ultrafine grains will grow and participate in the process supporting some of the load. The effective average grain size in the material is, therefore, refined, leading to a decrease in flow stress with strain according to the inverse dependence of the steady-state strain rate with grain size (Eq. (1)), as experimentally observed (Fig. 2).

With the previous statement, the microstructure of the samples can be regarded as constant up to the peak stress $\sigma p$, regardless of testing conditions. The steady-state equation for flow (Eq. (1)) can be thus written as: 
$\dot{\varepsilon}=B \sigma_{p}^{n}$

where $\mathrm{B}$ is a constant independent of stress. The stress exponent $\mathrm{n}$ can be estimated from a plot of log View the MathML source versus peak stress $\sigma p$ at a given temperature, as shown in Fig. 5 for $\mathrm{T}=1300{ }^{\circ} \mathrm{C}$. A value of $\mathrm{n}=1.8$ was found, which is in close agreement with the value of 2 systematically reported in fine-grained metals and ceramics, 27 and 28 where grain boundary sliding is the dominant deformation mechanism. A stress exponent of 2 has been also predicted by many theoretical models developed to explain the superplastic behavior of fine-grained materials based on diffusion and/or dislocation slip.28 None of them, however, is able to explain successfully the body of experimental data; this is presently a matter of intense debate. The value of $\mathrm{n}=1.8$ experimentally found in fine-grained BC5Y substantiates the previous conclusion, based on microstructural observations about the retention of equiaxed grain shapes during creep, that grain boundary sliding plays a key role in the deformation of these compounds.

When deformation is achieved by grain boundary sliding, the steady-state flow generally is controlled by the diffusion necessary to accommodate the stresses generated during sliding.27 and 28 Thus, the activation energy for flow Q (Eq. (1)) must correspond to the activation energy of the slowest moving species in the compound. A value of $\mathrm{Q}=390 \pm 40 \mathrm{~kJ} / \mathrm{mol}$ was determined from an Arrhenius plot of log op versus reciprocal temperature $1 / \mathrm{T}$ at fixed initial strain rates. Unfortunately, there are not enough diffusion data available for $\mathrm{BCY}$ to make a precise comparison. Only the activation energy for oxygen bulk diffusion $\mathrm{Q} \approx 60 \mathrm{~kJ} / \mathrm{mol}$ has been reported, 15 which is substantially smaller than the value for creep, and suggests that cation diffusion is the rate-limiting process. The lack of comprehensive cation bulk and grain boundary diffusivities precludes a definitive identification of the rate-controlling species.

Two previous works15 and 16 focused on the high-temperature deformation of $\mathrm{BaCe} 1-\mathrm{xYxO} 3-\delta$, with $\mathrm{x}$ varying between 0.05 and 0.20 , grain sizes ranging from 2 to $9 \mu \mathrm{m}$ and relative densities of about $90 \%$ of theoretical values. In these studies, a stress exponent close to unity and an activation energy for creep of $360 \pm 60 \mathrm{~kJ} / \mathrm{mol}$ were reported. These values, along with the fact that grains did not change shape during testing, allowed the authors to conclude that the deformation was achieved by grain boundary sliding accommodated by cation lattice diffusion. The same conclusion was drawn in the deformation of other oxide perovskites with grain sizes ranging between 2 and $50 \mu \mathrm{m}$, where a stress exponent of about 1 was systematically found: $\begin{array}{lll}\mathrm{La} 0.9 \mathrm{Sr} 0.1 \mathrm{MnO} 3,29 & \mathrm{La} 0.8 \mathrm{Sr} 0.2 \mathrm{Ga} 0.85 \mathrm{Mg} 0.15 \mathrm{O} 2.825,30 \quad \text { BaTiO3,31 }\end{array}$ $\mathrm{La} 0.2 \mathrm{Sr} 0.8 \mathrm{Fe} 0.8 \mathrm{Cr} 0.2 \mathrm{O} 332$ and $\mathrm{SrCo} 0.8 \mathrm{Fe} 0.2 \mathrm{O} 333$. The difference in stress exponent values between these studies $(\mathrm{n} \approx 1)$ and the present work $(\mathrm{n} \approx 2)$ can be related with the difference in grain sizes. A transition from $n=1$ towards $n=2$ with decreasing grain size has been noted for other ceramic oxides 27 and 34; the critical grain size seems to be about $1 \mu \mathrm{m}$, in agreement with the present results. Nevertheless, diffusion is the ratelimiting step in both cases; the values of Q measured in fine- and large-grained BCY (390 and $360 \mathrm{~kJ} / \mathrm{mol}$, respectively) compare very well and suggest that cation lattice 
diffusion is also the rate-controlling mechanism for grain boundary sliding in the $\mathrm{n}=2$ region. It is worth noting that the same mechanism was proposed for the superplastic behavior of fine-grained tetragonal zirconia. 27

\section{Conclusions}

Polycrystalline $\mathrm{BaCe} 0.95 \mathrm{Y} 0.05 \mathrm{O} 3-\delta$ with average grain size of $0.40 \mu \mathrm{m}$ was strained in compression between 1100 and $1300{ }^{\circ} \mathrm{C}$ in air at various constant initial strain rates. The true stress-true strain curves systematically displayed an initial strength drop followed by an extensive steady-state regime, except at the most severe deformation conditions (lowest temperatures and highest strain rates) where catastrophic fracture occurred. The yield stress showed strong dependence on temperature and on the applied strain rate. No change in grain shape was observed after $50 \%$ strain, indicating that grain boundary sliding is the main deformation mechanism in this compound, as also found in fine-grained superplastic materials. The stress drop has been correlated with the growth of ultrafine grains present previously at grain boundaries and triple grain junctions in the as-fabricated material. A stress exponent $\mathrm{n}=1.8$ and an activation energy for flow $\mathrm{Q}=390 \mathrm{~kJ} / \mathrm{mol}$ were estimated from mechanical. The $\mathrm{n}$ value is consistent with grain boundary sliding accommodated by diffusion. By comparison with large-grained oxide perovskites, it is suggested that deformation is rate-controlled by bulk cation diffusion.

\section{Acknowledgment}

This work was supported by the Project no. MAT2009-13979-C03-01, Ministerio de Ciencia e Innovación, Spain. 


\section{References}

1. B.C.H. Steele

Survey of materials selection for ceramic fuel cells II. Cathodes and anodes

Solid State Ionics, 86-88 (Part 2) (1996), pp. 1223-1234

2. T. Tagawa, K.K. Moe, T. Hiramatsu, S. Goto

Design of electrode for solid oxide fuel cells reactor

Solid State Ionics, 106 (3-4) (1998), pp. 227-235

3. C.H. Chen, H.J.M. Bouwmeester, R.H.E. van Doorn, H. Kruidhof, A.J. Burggraaf

Oxygen permeation of $\mathrm{La} 0.3 \mathrm{Sr} 0.7 \mathrm{CoO} 3-\delta$

Solid State Ionics, 98 (1-2) (1997), pp. 7-13

4. J. Guan, S.E. Dorris, U. Balachandran, M. Liu

Transport properties of $\mathrm{BaCe} 0.95 \mathrm{Y} 0.05 \mathrm{O} 3-\alpha$ mixed conductors for hydrogen separation

Solid State Ionics, 100 (1-2) (1997), pp. 45-52

5. T. Shimada, C. Wen, N. Taniguchi, J. Otomo, H. Takahashi

The high temperature proton conductor $\mathrm{BaZr} 0.4 \mathrm{Ce} 0.4 \mathrm{In} 0.2 \mathrm{O} 3-\alpha$

J. Power Sources, 131 (1-2) (2004), pp. 289-292

6. G-y. Adachi, N. Imanaka

Rare earth contribution in solid state electrolytes, especially in the chemical sensor field J Alloys Compd, 250 (1-2) (1997), pp. 492-500

7. R. Costa, J. Hafsaoui, A.P. Almeida de Oliveira, A. Grosjean, M. Caruel, A. Chesnaud et al.

Tape casting of proton conducting ceramic material

J Appl Electrochem, 39 (4) (2009), pp. 485-495

8. J.-H. Kim, H.-I. Yoo

Partial electronic conductivity and electrolytic domain of $\mathrm{La} 0.9 \mathrm{Sr} 0.1 \mathrm{Ga} 0.8 \mathrm{Mg} 0.2 \mathrm{O} 3-\delta$

Solid State Ionics, 140 (1-2) (2001), pp. 105-113

9. F. Iguchi, T. Tokikawa, T. Miyoshi, T. Tsurui, Y. Nagao, N. Sata et al. 
Performance of $\mathrm{BaZrO} 3$ based proton conductors as an electrolyte for intermediate temperature operating SOFC

ECS Trans, 7 (1) (2007), pp. 2331-2336

10. H. Iwahara

Technological challenges in the application of proton conducting ceramics

Solid State Ionics, 77 (1995), pp. 289-298

11. H. Maekawa, Y. Ukei, K. Morota, N. Kashii, J. Kawamura, T. Yamamura

High temperature proton NMR study of yttrium doped barium cerates

Solid State Commun, 130 (1-2) (2004), pp. 73-77

12. N. Bonanos

Transport properties and conduction mechanism in high-temperature protonic conductors

Solid State Ionics, 53-56 (Part 2) (1992), pp. 967-974

13. W.G. Coors

Steam reforming and water-gas shift by steam permeation in a protonic ceramic fuel cell

J Electrochem Soc, 151 (7) (2004), pp. A994-A997

14. W.G. Coors

Protonic ceramic steam-permeable membranes

Solid State Ionics, 178 (7-10) (2007), pp. 481-485

15. K.C. Goretta, E.T. Park, J. Guan, U. Balachandran, S.E. Dorris, J.L. Routbort

Diffusional creep of $\mathrm{BaCe} 0.8 \mathrm{Y} 0.2 \mathrm{O} 3-\alpha$ mixed conductors

Solid State Ionics, 111 (3-4) (1998), pp. 295-299

16. E.T. Park, K.C. Goretta, A.R. de Arellano-López, J. Guan, U. Balachandran, S.E. Dorris et al.

High-temperature deformation of $\mathrm{BaCe} 1-\mathrm{xYxO}-\mathrm{y}(0.05 \leq \mathrm{x} \leq 0.2)$

Solid State Ionics, 117 (3-4) (1999), pp. 323-330

17. P. Cordier, Y. Ungár, L. Zsoldos, G. Tichy

Dislocation creep in $\mathrm{MgSiO} 3$ perovskite at conditions of the Earth's uppermost lower mantle 
Nature, 428 (2004), pp. 837-840

18. S. Merkel, H.R. Wenk, J. Badro, G. Montagnac, P. Gillet, H-k. Mao et al.

Deformation of $(\mathrm{Mg} 0.9 \mathrm{Fe} 0.1) \mathrm{SiO} 3$ perovskite aggregates up to $32 \mathrm{GPa}$

Earth Planet Sci Lett, 209 (3-4) (2003), pp. 351-360

19. Y.C. Lin, M.-S. Chen, J. Zhong

Prediction of 42CrMo steel flow stress at high temperature and strain rate

Mech Res Commun, 35 (2008), pp. 142-150

20. S.-M. Zhu, K. Sakamoto, M. Tamura, K. Iwasaki

A comparative study of the high temperature deformation behavior of $\mathrm{Fe}-25 \mathrm{Al}$ and $\mathrm{Fe}-$ 25Al-10Ti alloys

Scripta Mater, 42 (9) (2000), pp. 905-910

21. T. Sakai, J.J. Jonas

Dynamic recrystallization: mechanical and microstructural considerations

Acta Metal, 32 (2) (1984), pp. 189-209

22. S. Solhjoo

Analysis of flow stress up to the peak at hot deformation

Mater Des, 30 (8) (2009), pp. 3036-3040

23. H.J. McQueen, N.D. Ryan

Constitutive analysis in hot working

Mater Sci Eng A, 322 (1-2) (2002), pp. 43-63

24. P.C. Dokko, J.A. Pask

High-temperature stress-strain behavior of $\mathrm{MgO}$ in compression

J Am Ceram Soc, 62 (9-10) (1979), pp. 433-439

25. T. Tachibana, H. Furuya, M. Koizumi

Dependence on strain rate and temperature shown by yield stress of uranium dioxide

J Nucl Sci Technol, 13 (9) (1976), pp. 497-502

26. K. Morita, B.-N. Kim, K. Hiraga, Y. Sakka 
Yield drop in high-strain-rate superplastic deformation of $\mathrm{ZrO} 2-30$ vol\% MgAl2O4 spinel composite

Phil Mag Lett, 83 (9) (2003), pp. 533-541

27. M. Jiménez-Melendo, A. Domínguez-Rodríguez, A. Bravo-León

Superplastic flow of fine-grained yttria-stabilized zirconia polycrystals: constitutive equation and deformation mechanisms

J Am Ceram Soc, 81 (11) (1998), pp. 2761-2776

28. T.G. Nieh, J. Wadsworth, O.D. Sherby

Superplasticity in metals and ceramics

Cambridge University Press, Cambridge (1997)

29. J. Wolfenstine, T.R. Armstrong, W.J. Weber, M.A. Boling-Risser, K.C. Goretta, J.L. Routbort

Eleated temperature deformation of fine-grained $\mathrm{La} 0.9 \mathrm{Sr} 0.1 \mathrm{MnO} 3$

J Mater Res, 11 (3) (1996), pp. 657-662

30. J. Wolfenstine

Rate-controlling species for creep of the solid state electrolyte: doped lanthanum gallate

Solid state Ionics, 126 (3) (1999), pp. 293-298

31. T.E. Park, P. Nash, J. Wolfenstine, K.C. Goretta, J.L. Routbort

High-temperature creep of polycrystalline BaTiO3

J Mater Res, 14 (2) (1999), pp. 523-528

32. G. Majkic, L.T. Wheeler, K. Salama

High-temperature deformation of $\mathrm{La} 0.2 \mathrm{Sr} 0.8 \mathrm{Fe} 0.8 \mathrm{Cr} 0.2 \mathrm{O} 3-\delta$-mixed ionic-electronic conductor

Solid State Ionics, 146 (3) (2002), pp. 393-404

33. G. Majkic, L.T. Wheeler, K. Salama

Creep of polycrystalline $\mathrm{SrCo} 0.8 \mathrm{Fe} 0.2 \mathrm{O} 3-\delta$

Acta Mater, 48 (8) (2000), pp. 1907-1917

34. A. Morales-Rodríguez, A. Domínguez-Rodríguez, G. de Portu, M. JiménezMelendo 
Creep mechanisms of laminated alumina/zirconia-toughened alumina composites

J Eur Ceram Soc, 29 (9) (2009), pp. 1625-1630 


\section{Figure captions}

Figure 1. HRSEM micrograph of polished and thermally etched cross-section of asfabricated $\mathrm{BaCe}_{0.95} \mathrm{Y}_{0.05} \mathrm{O}_{3-\delta}$ polycrystal.

Figure 2. True stress vs true strain curves for polycrystals: (a) at $1300{ }^{\circ} \mathrm{C}$ as a function of the initial strain rate $\dot{\varepsilon}_{o}$; and (b) at $\dot{\varepsilon}_{0}=6.6 \times 10^{-5} \mathrm{~s}^{-1}$, as a function of temperature. A transition from steady-state flow to controlled flow softening and eventually to catastrophic failure can be observed.

Figure 3. HRSEM micrograph of polished and thermally etched cross-section of 50\%strained polycrystal $\left(\mathrm{T}=1300{ }^{\circ} \mathrm{C} \quad \dot{\varepsilon}_{0}=6.6 \times 10^{-5} \mathrm{~s}^{-1}\right.$ The compressive axis is vertical.

Figure 4. HRSEM micrographs of fracture surfaces of: (a) undeformed specimen; (b) $50 \%$-strained specimen at $\mathrm{T}=1300{ }^{\circ} \mathrm{C}$ and $\dot{\varepsilon}_{0}=6.6 \times 10^{-5} \mathrm{~s}^{-1} ;$ and (c) catastrophically failed specimen at $\mathrm{T}=1300{ }^{\circ} \mathrm{C}$ and $\dot{\varepsilon}_{\mathrm{o}}=1.6 \times 10^{-3} \mathrm{~s}^{-1}$.

Figure 5. Variation of strain rate with peak stress at $1300{ }^{\circ} \mathrm{C}$. The stress exponent is the slope of the best linear fit. 
Figure 1

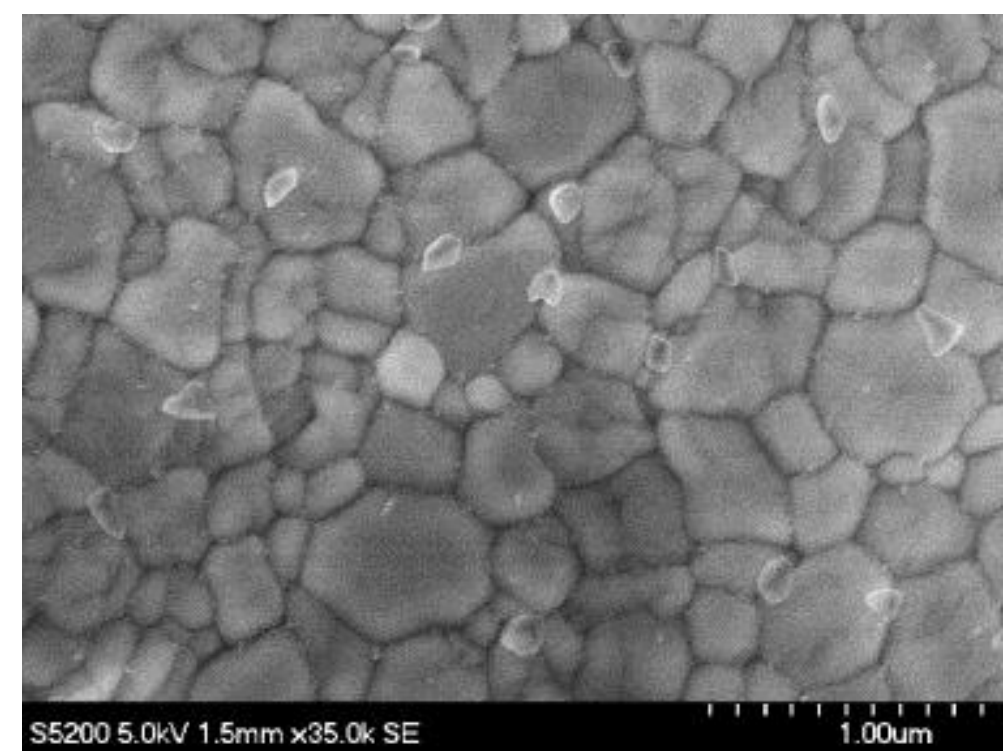


Figure 2.
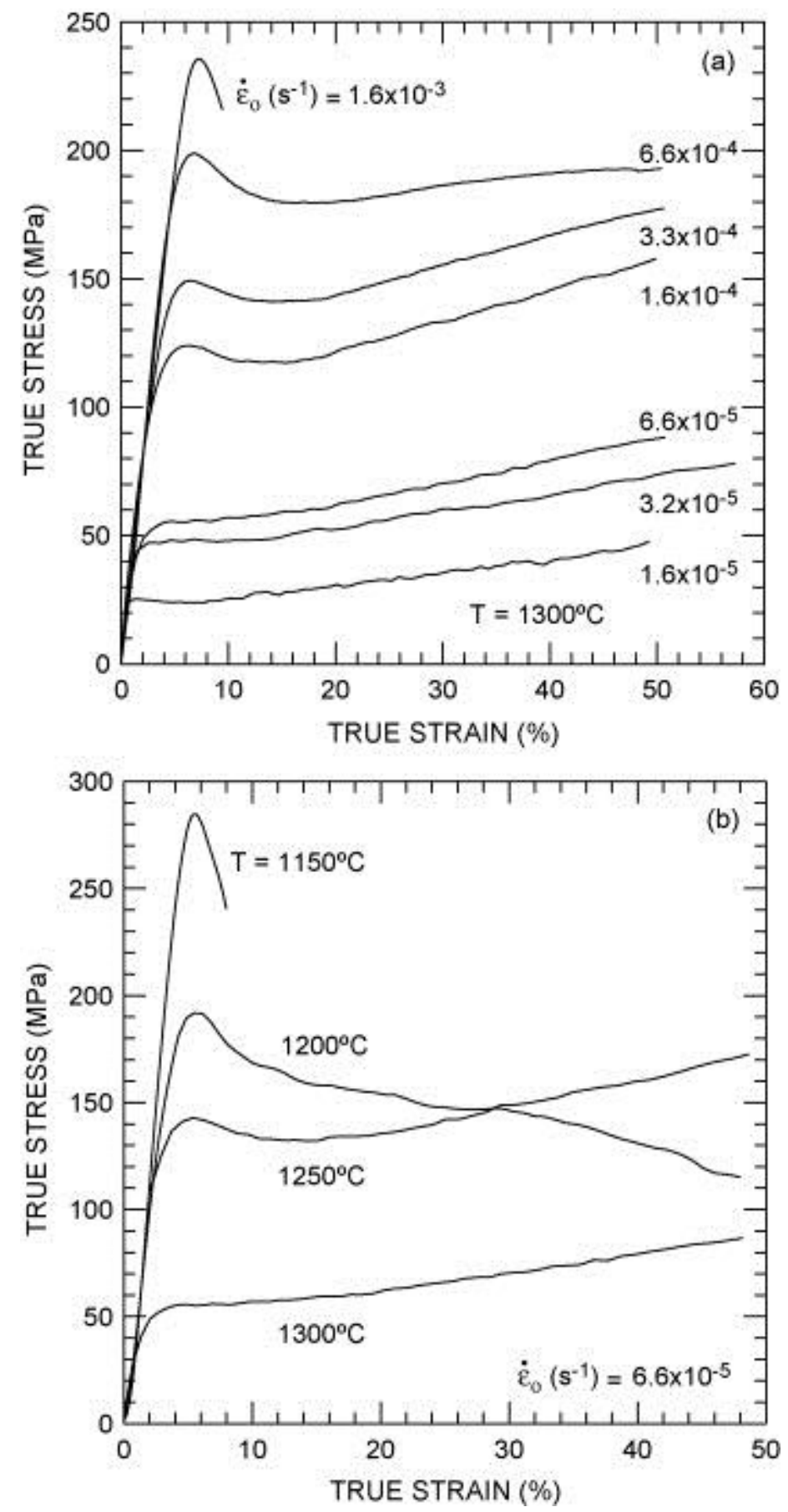
Figure 3

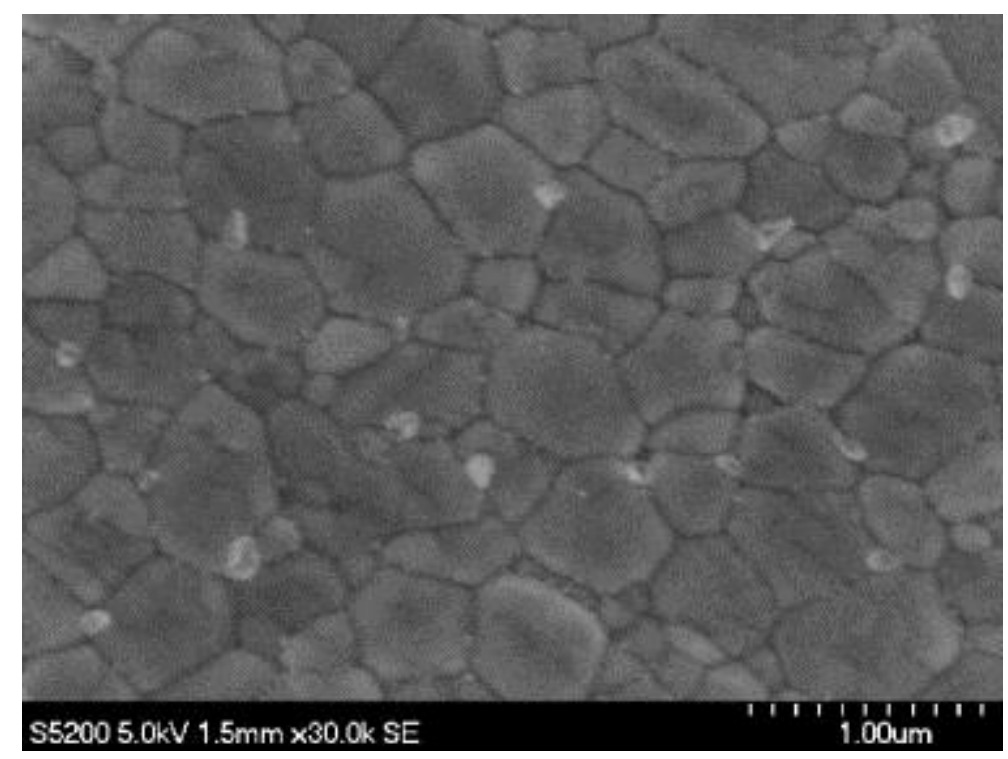


Figure 4
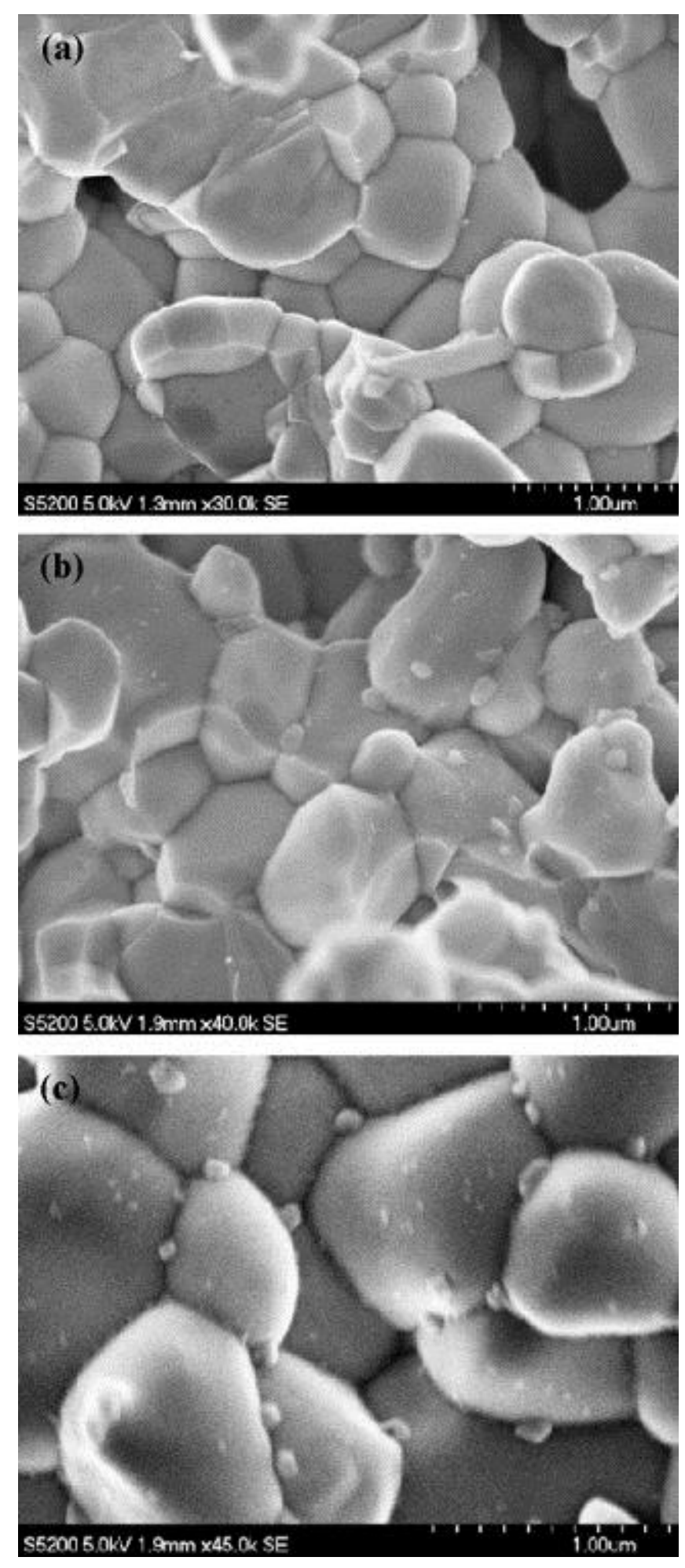
Figure 5

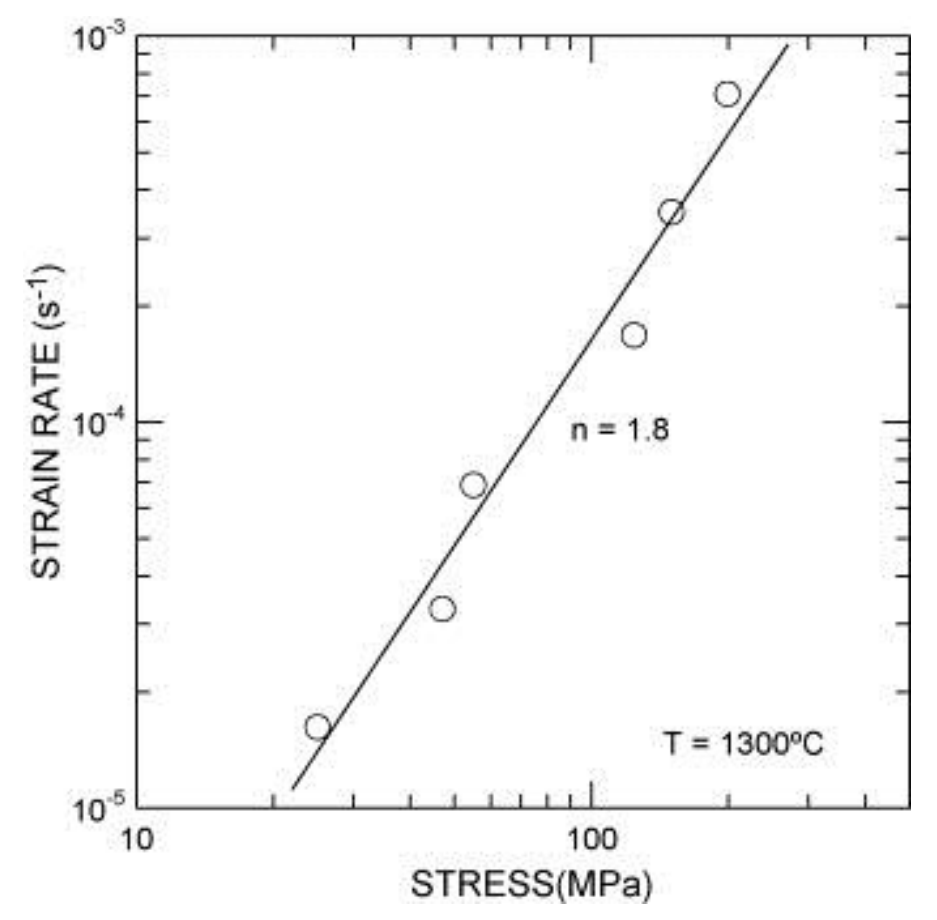

